\title{
Neuroimaging in Pediatric Stroke and Cerebrovascular Disease
}

\author{
Adam E. Goldman-Yassen ${ }^{1}$ - Seena Dehkharghani² \\ ${ }^{1}$ Department of Radiology and Imaging Sciences, Emory University and Children's \\ Healthcare of Atlanta, Atlanta, GA, USA; ${ }^{2}$ Departments of Radiology and Neurology, \\ New York University Langone Medical Center, New York, NY, USA
}

Author for correspondence: Adam E. Goldman-Yassen, Department of Radiology and Imaging Sciences, Emory University and Children's Healthcare of Atlanta, Atlanta, GA, USA. Email: aegold5@emory.edu

Doi: https://doi.org/10.36255/exonpublications.stroke.pediatricstroke.2021

\begin{abstract}
Although less common than in adults, stroke is the sixth leading cause of death in children, affecting 2-13 children per 100,000 under 18 years of age. Because it is underappreciated clinically, the diagnosis of pediatric stroke is often delayed or even missed, or misdiagnosed as more common conditions such as migraine, epilepsy, or viral illnesses. Since pediatric stroke is caused by unique etiologies and can present differently than in adults, diagnostic imaging should be tailored to the specific and diverse causative entities and distinctive needs of the pediatric population. This chapter provides a comprehensive review of pediatric stroke, including the etiologies, diagnosis, and management, emphasizing the role of neuroimaging in diagnostic and treatment pathways. Understanding the distinct clinical entity of pediatric stroke and the role of imaging in diagnosis is important for early detection and treatment of this underappreciated disease.
\end{abstract}

Keywords: arterial ischemic stroke; hemorrhagic stroke, ischemic stroke; neuroimaging; pediatric stroke

In: Stroke. Dehkharghani S (Editor). Exon Publications, Brisbane, Australia. ISBN: 978-0-6450017-6-1; Doi: https://doi.org/10.36255/exonpublications.stroke.2021

Copyright: The Authors.

License: This open access article is licenced under Creative Commons Attribution-NonCommercial 4.0 International (CC BY-NC 4.0) https://creativecommons.org/licenses/by-nc/4.0/ 


\section{INTRODUCTION}

Stroke is increasingly recognized as an important cause of morbidity and mortality in the infant and child, now among the top 10 causes of childhood death (1-4). While not as common as in adults, stroke affects 2.3 to 13 children per 100,000 per year (4-9). The etiologies and presentation of stroke in children may be different than in adults and vary with age, often resulting in delayed or missed diagnosis. Accurate recognition of childhood stroke is important for the rapid implementation of targeted and neuroprotective therapies. It is therefore important that clinicians be familiar with risk factors, etiologies, and treatment of pediatric stroke.

Etiologic and developmental differences in children limit extrapolation from the adult stroke experience to pediatric patients. Neuroimaging is nevertheless essential for accurate diagnosis, as well as for differentiating stroke from stroke mimics and in guiding therapy. In this chapter, we discuss the unique causes of arterial ischemic, hemorrhagic, and venous stroke in the pediatric population and the role of imaging in diagnosis, treatment decisions, and long-term prognosis. Imaging patterns in primary energetic failure, such as from mitochondrial disorders, and diffuse ischemic or inflammatory brain injury, including hypoxic ischemic encephalopathy, are beyond the scope of this chapter and are reviewed elsewhere $(10,11)$. Because of the unique and varied causes of pediatric stroke and the need for accurate and timely diagnosis, the neuroimaging and the unique etiologies, presentations, and management of pediatric stroke will be the focus of the following discussion.

\section{DEFINITIONS}

Pediatric stroke, which occur between 29 days and 18 years of age, can be divided into ischemic and hemorrhagic etiologies. Ischemic stroke, with parenchymal injury related to loss of perfusion in a vascular territory, occurs in $55 \%$ of pediatric strokes and can be caused by arterial ischemic stroke (AIS) or venous infarction (4). Transient ischemic attach (TIA), defined in adults as sudden onset of focal neurologic symptoms that resolve fully within 24 hours and without radiologic ischemia, is less common in children; however, $6 \%$ of children with transient neurologic symptoms may demonstrate evidence for ischemia on acute imaging and $13 \%$ of children with TIA may eventually progress to strokes (12). Hemorrhagic strokes, by comparison, comprise nontraumatic intracerebral hemorrhage, intraventricular, and/or subarachnoid intracranial hemorrhage (13).

\section{CLINICAL PRESENTATION}

Since the clinical presentation of stroke in children and infants can be unrecognized or an alternative diagnosis may be favored, imaging is often the most revealing aspect of the diagnostic workup. Acute stroke can present with seizure, altered mental status, headache, and lethargy in children. Perinatal stroke diagnosed later 
in infancy or in childhood (presumed perinatal ischemic stroke) manifests with early hand preference, developmental delay, motor impairment, and seizures (14). Older infants and children can present with symptoms similar to those in adults, with acute onset of neurologic deficits (15).

\section{ETIOLOGIES}

The causes of stroke in children vary with age and relate to often different etiologies than those in adult stroke. Childhood strokes may be associated with vasculopathies (inherited or acquired), infection/inflammation, genetic/metabolic disorders, cardiac disorders, or disorders of coagulation (Table 1) (16-20).

\section{TABLE 1 Medical Conditions Associated with Childhood Arterial Ischemic Stroke and Cerebral Sinovenous Thrombosis (20)}

Vasculopathy

- Sickle cell disease

- Moyamoya syndrome

- Alagille syndrome

- Grange Syndrome

- Acardi-Goutières Syndrome

- ADAMTS13 thrombotic microangiopathy

- ACTA2 mutation

- Cerebroretinal Vasculopathy and Hereditary Endotheliopathy With Retinopathy, Nephropathy, and Stroke Syndrome

- Radiation vasculopathy

- Arterial dissection

- Collagen vascular disorders:

- Ehlers-Danlos type IV

- Marfan syndrome

- COL4Al mutations

- Fibromuscular dysplasia

- Focal cerebral arteriopathy

- Primary angiitis of the central nervous system

- Systemic vasculitides and autoimmune disorders:
- Wegener granulomatosis
- Microscopic polyangiitis
- Polyarteritis nodosa 


\section{TABLE 1 Medical Conditions Associated with Childhood Arterial Ischemic Stroke and Cerebral Sinovenous Thrombosis (20) (Continued)}

- Takayasu arteritis

- Systemic lupus erythematosus

- Mixed connective tissue disease

○ Henoch-Schönlein purpura

- Hemophagocytic lymphohistiocytosis

- Kawasaki disease

- Inflammatory bowel disease

- Human immunodeficiency virus

- Vasospasm:

- Reversible cerebral vasoconstriction syndrome

- Subarachnoid hemorrhage

- Cocaine use

\section{Prothrombotic conditions}

- Polycythemia

- Deficiency of protein C, protein S, antithrombin III

- Factor V Leiden mutation/activated protein C resistance

- Prothrombin 20210 gene mutation

- Elevated factor VIII

- Elevated von Willebrand factor antigen

- Hyperhomocysteinemia (MTHFR mutation)

- Elevated lipoprotein(a)

- Antiphospholipid antibodies

- Migraine with aura

- Estrogen-containing oral contraceptive use

- Pregnancy and postpartum

- Malignancy

- L-asparaginase and other chemotherapeutics

\section{Cardiac disorders}

- Congenital heart disease, especially with right-to-left shunt

- Cardiac catheterization or surgery

- Extracorporeal membrane oxygenation

- Left ventricular assist devices

- Endocarditis

- Valvular abnormalities

- Cardiomyopathy 


\section{TABLE 1
Medical Conditions Associated with Childhood Arterial Ischemic Stroke and Cerebral Sinovenous Thrombosis (20) (Continued)

Genetic/metabolic disorders

- Mitochondrial encephalopathy, lactic acidosis, and stroke-like episodes (MELAS)

- Cerebral autosomal dominant arteriopathy with subcortical infarcts and leukoencephalopathy (CADASIL)

- Cathepsin A-related arteriopathy with strokes and leukoencephalopathy (CARASAL)

- Cerebral autosomal recessive arteriopathy with subcortical infarcts and leukoencephalopathy (CARASIL)

- Homocystinuria

- Fabry disease

- Menkes Disease

- Organic acidemias:

- Glutaric aciduria type II

- Methylmalonic acidemia

- Propionic acidemia

- Isovaleric acidemia

- Congenital disorders of glycosylation

- Adenosine deaminase 2 deficiency

- Sulfite oxidase deficiency

- Pseudoxanthoma Elasticum

\section{Infection}

- Meningitis
- Streptococcus pneumoniae
- Tuberculosis
- Aspergillus species

- Varicella vasculopathy

- Sinusitis

- Mastoiditis

- Sepsis

- COVID-19

\section{Arterial ischemic stroke}

Focal cerebral arteriopathy (FCA), also known as transient cerebral arteriopathy, is a common cause of pediatric AIS in previously healthy children (Figure 1) $(16,17,21-24)$. Defined by an acute, monophasic illness causing unilateral stenosis of the intracranial cerebral arteries, mainly involving the anterior circulation, FCA was found in 36\% of children presenting with acute stroke in one 


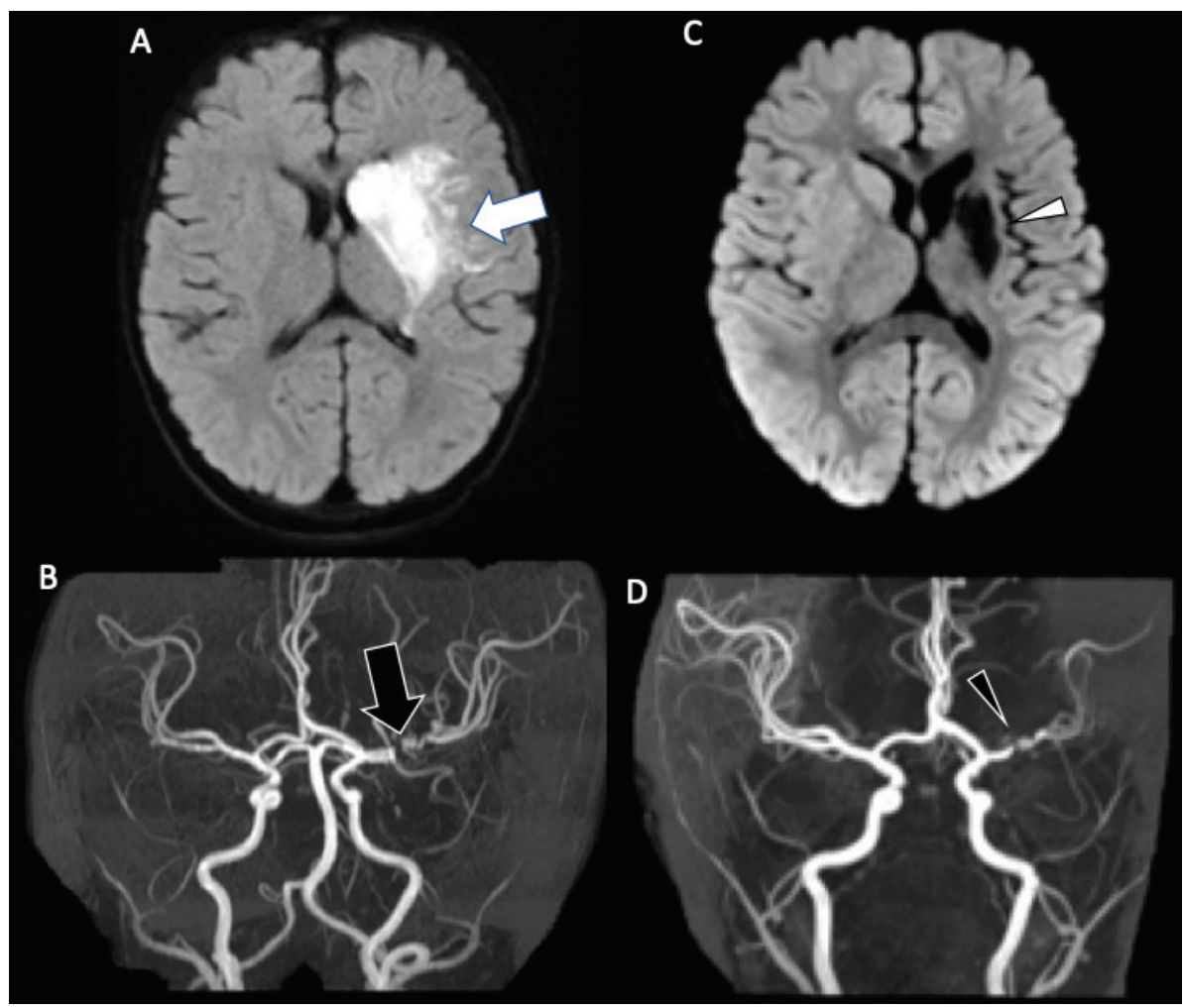

Figure 1. A six-month-old male who presented with acute right hemiparesis. DWI

(A) demonstrates acute infarct in the left basal ganglia and deep white matter (white arrow). MRA (B) shows severe stenosis of the left M1 middle cerebral artery segment (black arrow). Follow-up 4 months later, demonstrates evolution of the infarct, now with encephalomalacia and gliosis without new acute infarct (white arrowhead) (C). MRA at that times shows mild improvement but persistent MCA stenosis (black arrowhead) (D). Findings are most compatible with focal cerebral arteriopathy.

series (23). FCA can be further subdivided into the following subtypes: FCA- dissection type (FCA-d), FCA-inflammatory type (FCA-i), primary and secondary Moyamoya disease, genetic or syndromic arteriopathies (such as PHACE syndrome), vasculitis, fibromuscular dysplasia, and iatrogenic forms (Figures 2) $(25,26)$. The appropriate diagnosis is important to establish because prognosis can be improved by treatment of the inflammation, when present. FAC-i is associated with viral infection and vaccination may reduce the incidence $(16,17$, $24,27)$. Varicella zoster virus (VZV) is an established cause of FCA, although other pathogens, including other herpes viruses, likely play a role as FCA continues to occur in VZV vaccinated children $(16,28,29)$. Age of onset differs between arteriopathy subtypes, with FCA-i tending to affect older school-aged children, Moyamoya affecting younger children, and dissection generally presenting no age predilection (30). COVID-19 has been reported as a cause of FCA, also resulting 


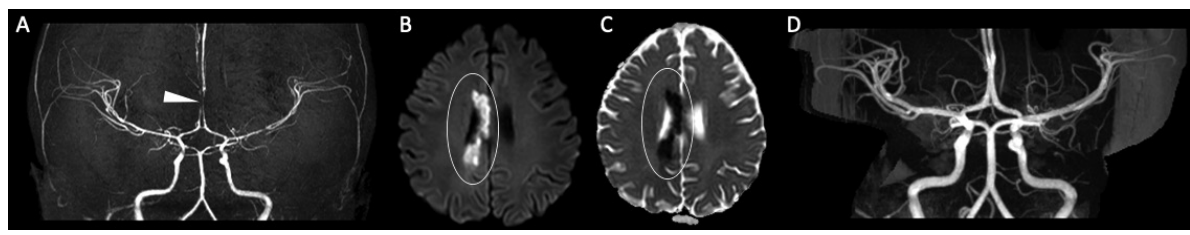

Figure 2. A six-year-old female with B-ALL receiving intrathecal methotrexate and Cerubidine, presenting with new left facial palsy. MR angiography $(\mathbf{A})$ demonstrates multifocal stenosis of the intracranial arteries, most severe along the right ACA (white arrowhead), likely representing vasculitis. DWI (B) and corresponding ADC map (C) demonstrate diffusion restriction along the right aspect of the corpus callosum and paramedian frontal and parietal lobes (white circle). Follow-up MRA (D) demonstrates resolution of arterial stenoses.

stroke related to the prothrombotic effects leading to AIS and venous sinus thrombosis (31-33). Inherited vasculopathies include, such as mutation in ACTA2, with distinctive imaging features which may suggest such diagnoses (34). Disorders of coagulation may be identified, including deficiencies of proteins $\mathrm{C}$ and S, G20210A prothrombin mutations, and factor V Leiden, as well as the presence of anticardiolipin antibodies $(19,35-38)$. In patients with no underlying metabolic disorders, trauma and previous viral infection are significantly more common $(16,17,39,40)$. Genetic or acquired conditions causing thrombophilia are less common causes (41).

\section{Hemorrhagic stroke}

The incidence of pediatric hemorrhagic stroke is 1.1 per 100,000 $(4,42)$. Causes of hemorrhagic stroke include venous sinus thrombosis, rupture of vascular malformations or aneurysms, coagulopathy, and hemorrhagic conversion of ischemic infarct (arterial or venous) (Table 2) (13, 20). Some genetic arteriopathies of childhood are associated with both pre- and post-natal hemorrhagic stroke, including collagen IVA (COL4A1 or COL4A2) or JAM3 mutations, which can appear identical to hemorrhagic venous infarction (43-50). Hemorrhage due to collagen IVA mutations can be mild, presenting with vasculopathy or leukoencephalopathy in teens and adults, or very severe, resulting in even prenatal, fetal hydranencephaly (51). Affected infants commonly present with seizures and diffuse neurologic signs, whereas older children more commonly manifest alteration of consciousness, headache, or focal neurologic signs (52).

\section{Venous infarct}

Venous infarcts secondary to cerebral sinovenous thrombosis (CSVT) are fairly common, both prenatally and in childhood (52). The incidence in childhood is between 0.4 and 0.7 per 100,000 children per year (52-54). Up to $40 \%$ suffer venous infarctions, of which approximately $70 \%$ are hemorrhagic (52). Venous thrombosis should be suspected in any child who has an unexplained hemorrhage or a brain injury not fitting an arterial vascular distribution in the absence of trauma or infection $(55,56)$. Risk factors include head and neck infections in preschool children and trauma or chronic diseases such as connective tissue 


\section{TABLE 2 Conditions Associated with Childhood Hemorrhagic Stroke (20)}

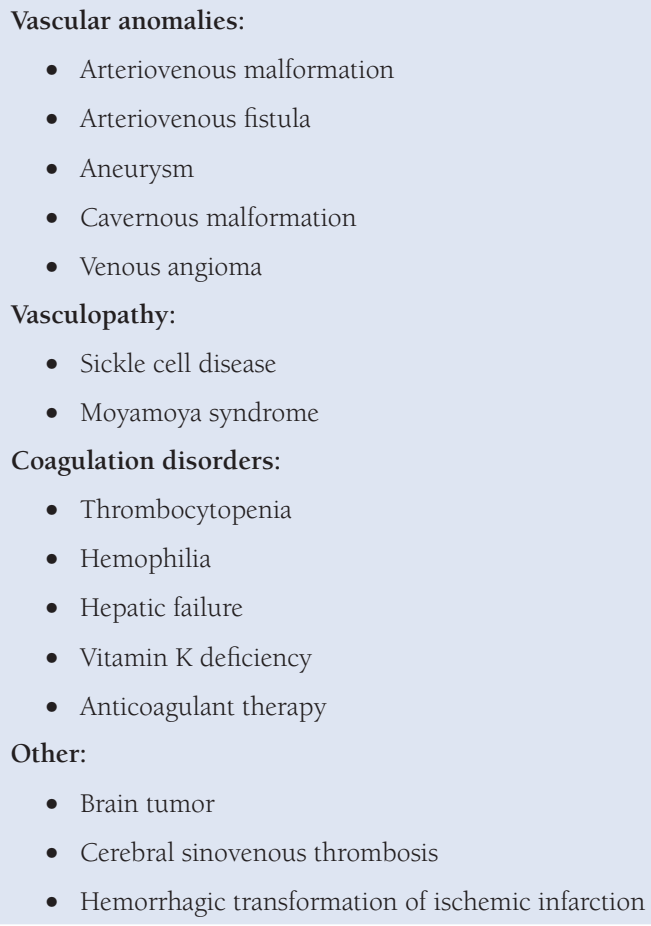

- Arteriovenous malformation

- Arteriovenous fistula

- Aneurysm

- Cavernous malformation

- Venous angioma

Vasculopathy:

- Sickle cell disease

- Moyamoya syndrome

Coagulation disorders:

- Thrombocytopenia

- Hemophilia

- Hepatic failure

- Vitamin K deficiency

- Anticoagulant therapy

Other:

- Brain tumor

- Cerebral sinovenous thrombosis

- Hemorrhagic transformation of ischemic infarction

disorders in older children $(52,55,57)$. If spontaneous venous thrombosis is identified, the patient should be evaluated for disorders of coagulation, such as factor V Leiden or proteins C and S, high coagulation factor VIII, G20210A prothrombin mutations, MTHFR polymorphism, increased lipoprotein A, and the presence of anticardiolipin antibodies $(37,55,58-65)$.

\section{IMAGING}

The role of imaging in pediatric stroke is to confirm the diagnosis of stroke, identify the etiology of the stroke, establish the timing of insult, document evolution, exclude stroke mimics, facilitate treatment decisions, and provide prognostic information.

\section{Choice of imaging modality}

The choice of radiologic study depends on the age of the patient, the clinical scenario, and the available hospital resources. Although requiring the use of ionizing 
radiation, non-contrast head CT (NCCT) is often the initial study in a child presenting with possible stroke due to the widespread availability, speed, and sensitivity for intracranial hemorrhage. However, NCCT has limited sensitivity for the detection of acute childhood AIS and stroke mimics, failing to identify the diagnosis in more than $40 \%$ of children (66). In children who are medically unstable, in whom MRI is contraindicated, or in environments unable to perform MRI rapidly, CT angiography of the head and neck, with or without CT venography (using either an equilibrium or additional venographic phase to ensure opacification of the venous system) may be preferable but remains a second-line option due to the considerably greater ionizing radiation doses inherent to high resolution, large coverage angiographic imaging as well as the dependency upon exogenous iodinated contrast dye.

MRI, MR arteriography (MRA), and MR venography (MRV), potentially with the addition of perfusion imaging, are preferred to obtain a definitive diagnosis of both ischemic and hemorrhagic lesions, as well as to identify underlying arteriopathy, thrombus, or arterial dissection in both neonates and older children (Figure 3). Because of limited scanner time and need for patient sedation, many centers have implemented rapid or abbreviated brain MRI protocols for stroke. The protocols typically include diffusion-weighted imaging (DWI) and apparent diffusion coefficient (ADC) maps to diagnose ischemic stroke as well as gradient echo (GRE) sequences or susceptibility-weighted imaging (SWI) to detect hemorrhage (67). Perfusion maps using arterial spin labeling (ASL) to assess for areas at risk can also be performed, if available, but are not extensively validated in pediatric stroke (68). Contrast-enhanced perfusion imaging using either dynamic bolus passage of gadolinium with rapid $\mathrm{T} 2 *$ weighting (i.e., dynamic susceptibility contrast, DSC) or Tl (dynamic contrast enhancement, DCE) are less often utilized in children; however, if intravenous contrast administration is already anticipated for remaining post-contrast brain imaging sequences, DSC can seamlessly be added with a nominal investment of time. Mural arteriography, or socalled vessel wall imaging (VWI), particularly with gadolinium enhancement has emerged for its sensitivity to disorders within the vessel wall, including in the

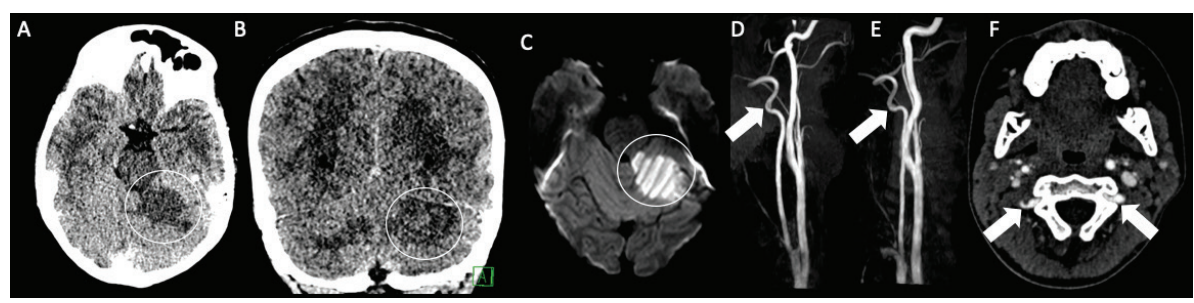

Figure 3. An 11-year-old previously healthy male who presented with left-sided headache, emesis and changing voice. Axial (A) and coronal (B) CT images of the head demonstrate a geographic region of hypoattenuation in the left superior cerebellar hemisphere with loss of grey-white differentiation (circle). C. Axial DWI from MRI the same day demonstrates corresponding reduced diffusion in the left superior cerebellar artery territory (circle). 2D Time-of-Flight MRA of the neck demonstrate irregularity of the right (D) and left (E) vertebral arteries at the junction of the V2 and V3 segments (arrows). Axial CT angiogram (F) confirms irregularity in the vertebral arteries, compatible with bilateral vertebral artery dissection (arrows). 
setting of active inflammatory process, such as in FCA, as well as to assess for intracranial arterial dissection on pre-contrast imaging (69).

Catheter angiography can be considered when the cause of the infarction is unclear from clinical or laboratory features, or non-invasive imaging studies, and when high clinical suspicion of an arteriopathy remains, due to its sensitivity for vasculopathy in medium and small vessels, shunt physiology, aneurysms, or other structural vascular disorders (70). Perfusion imaging is particularly important in the setting of vasculopathy such as moyamoya disease, when revascularization procedures such as bypass or synangiosis are considered, to assess hemodynamic changes before and after revascularization (71). We hasten to add that the use of commonly cited perfusion parameters in adult AIS, whether from DSC or CT perfusion, in the management of childhood AIS remains unestablished and considerable baseline anatomic, physiologic, and hemodynamic differences are to be anticipated.

\section{Arterial ischemic stroke}

AIS is defined as the presentation with a focal deficit or seizure that localizes to an ischemic area of brain injury in a known arterial territory. Knowledge of intracranial vascular territories and the predilections for certain pathologies may aid in narrowing the differential diagnosis. For example, posterior circulation infarctions are unusual in children and should raise suspicion for traumatic injury to the vertebrobasilar circulation, vasospasm secondary to migraine, or MELAS, particularly if the infarct is not in a strict vascular distribution (72-76). Thalamic strokes in older children typically occur in the setting of meningitis (infectious vasculitis), congenital heart disease, migraine, or trauma, while basal ganglia infarctions are often associated with infectious or parainfectious vasculopathy (i.e., FCA-i) $(17,77)$.

As noted above, while CT is often the first imaging modality performed, it is generally not the diagnostic modality of choice in children unless MRI is not available, or the child is too unstable. CT is sensitive for acute intracranial hemorrhage, appearing as hyperdense compared to normal parenchyma on non-contrast scans, but insensitive for hyperacute or small ischemic infarctions and more generally due to the widespread adoption of low-dose CT protocols in pediatric neuroimaging. If CT is obtained, cerebral infarction in the infant has a similar appearance to that in the older child or adult, manifesting as a well-defined, often wedge-shaped region of hypoattenuation in an arterial distribution.

MRI is the modality of choice in pediatric AIS. The MR appearance of infarctions in children and adolescents follows the appearance in adults (Table 3), as is the MR appearance of hemorrhagic infarcts. The sequence of choice to identify infarctions in the first few days is DWI, which shows reduced diffusivity within minutes of the infarction (78-80). The acute infarct is seen as high signal on DWI and low computed diffusivity values on accompanying ADC maps. Diffusivity remains reduced for several days, varying based upon the severity of injury and the presence, if any, of either spontaneous or therapeutic reperfusion, either of which may occur non-uniformly throughout the ischemic tissues. High signal on DWI increases continually in the hyperacute and acute phases, peaking commonly after several days under the combined influences of reduced diffusivity and 


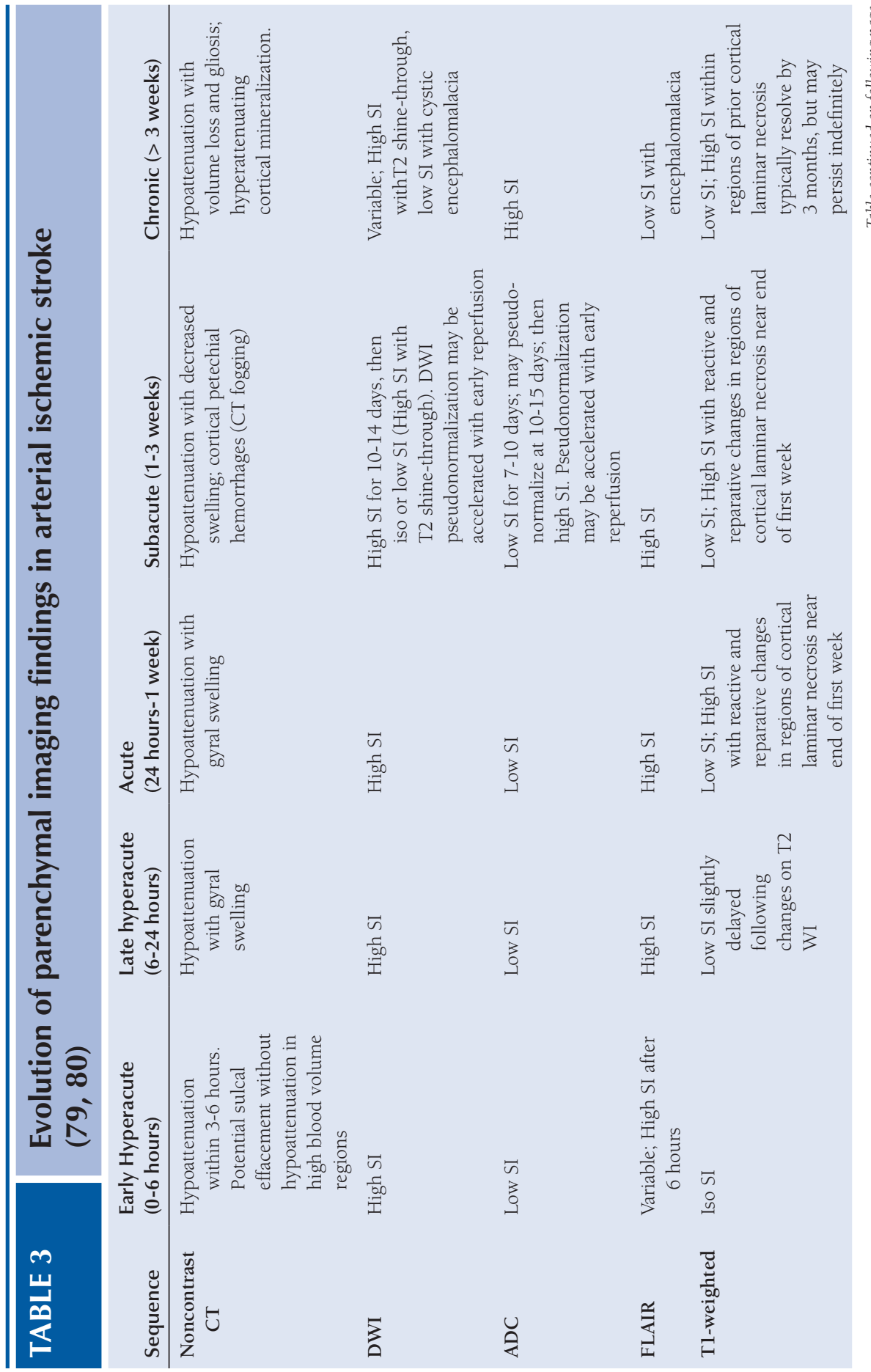




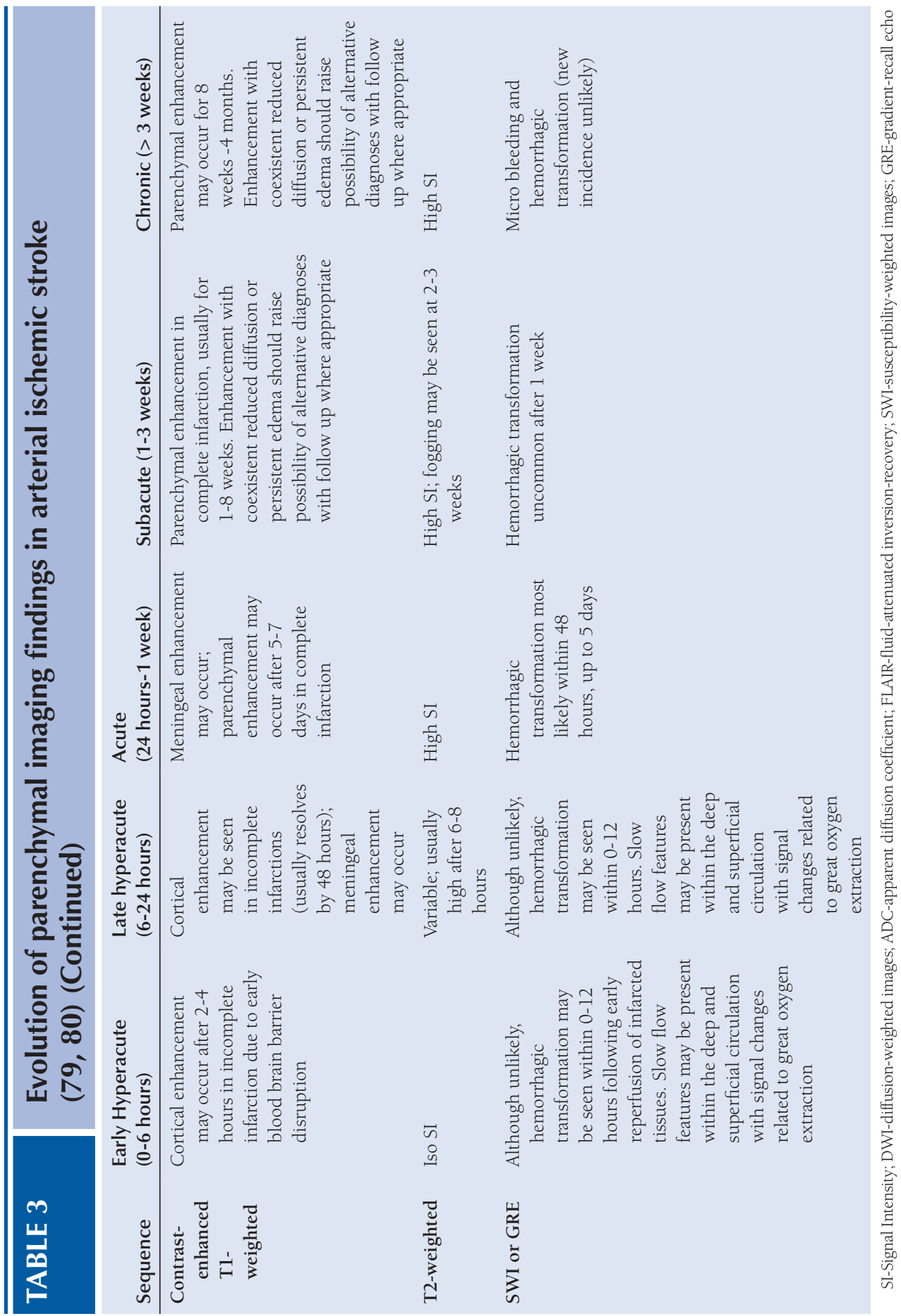


T2-shine through effects arising from increasing tissue water. Transient pseudonormalization either reducing or eliminating the visible changes in DWI may then be observed to last for a period of days of less, with diffusivity then increasing to supranormal levels, generally beginning near the second week (81-84). Importantly, the development and evolution of pseudonormalization on ADC will commonly precede that on DWI, potentially by many hours or even days, yet depends heavily upon the age of the patient, size of the stroke, severity of ischemia, how quickly collateral blood flow is recruited, and even technical variables related to diffusion imaging $(85,86)$.

Similar to the Alberta Stroke Program Early Computed Tomography Score (ASPECTS), which was developed as a system for scoring early ischemic changes on axial non-contrast CT and correlates highly with clinical outcomes, a pediatric modification of the ASPECTS (pedASPECTS) score was developed using DWI MRI (87-89). PedASPECTS has been shown to predict subsequent cerebral palsy, neurologic impairment, and epilepsy after symptomatic neonatal AIS (89). The score includes two regions of the anterior ( $\mathrm{A} 1$ and $\mathrm{A} 2$ ), 10 regions of the middle (M1, M2, M3, M4, M5, M6, insula, internal capsule, caudate, and lentiform nucleus), and three regions of the posterior cerebral artery territories (P1, P2, and thalamus) in each hemisphere. One point is allocated to each region affected by infarction; the total pedASPECTS ranges from 0 for normal to 30 for maximal severity (15 per hemisphere) (90).

Assessing AIS onset time is critical for the determination of whether a patient can be treated with tPA or thrombectomy. The mismatch between DWI and fluid attenuated inversion recovery (FLAIR) changes has been proposed for determination of the time window for potential intervention but may suffer significant interor intra-rater disagreement and subjectivity by comparison to quantitative alternatives $(91,92)$. In adults, DWI appears to reliably predict the core infarct and the DWI-perfusion weighted imaging (PWI) mismatch using DSC profiles may then be used to assess tissue at risk (penumbra) (93). Although a number of perfusion parameters, including mean transit time, time to peak, and time to maximum (Tmax) using various thresholds have been used for determination of the ischemic penumbra in adults, their validation in children is lacking. Although arterial spin labeling (ASL) is correlated with DSC perfusion parameters in assessment of mismatch in AIS, the correlation is imperfect and improved methods are needed before routine clinical use in acute stroke (94).

MRA can help define the site of stenosis, helping narrow the diagnosis in patients with arteriopathy, or identify a large vessel occlusion (Figure 4) (17, 23, 95, 96). A "banding" pattern is considered a pathognomonic feature for FCA-i but is less commonly identified by CTA or MRA than catheter angiography, presenting in less than one-quarter of cases, and is therefore specific but not sensitive for the diagnosis (Figure 5) (30). If arteriopathy is suspected and MRA is equivocal, vessel wall imaging, utilizing black-blood, Tl-weighted volumetric imaging after gadolinium can demonstrate abnormal vessel wall enhancement in the setting of active inflammatory processes, as well as assess for intracranial arterial dissection on pre-contrast T1-weighted imaging (69). Between 64\% and 74\% of arterial defects in pediatric ischemic infarctions are located in the supraclinoid carotid artery or Ml segment of the middle cerebral artery (70). Stenosis in FCA may change in appearance over the short term. Over the long term, they usually normalize ( $25 \%)$, stabilize after improvement $(32 \%)$, or stabilize (45\%) without 


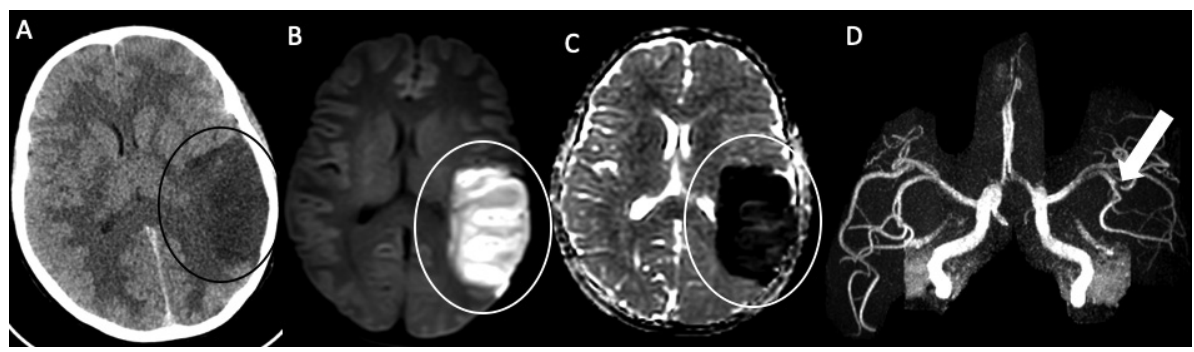

Figure 4. A 19-year-old female with a history of Down syndrome and repaired ASD and VSD.

The patient presented with 2 days of aphasia, alerted mental status, and right upper quadrant field cut. Axial CT (A) demonstrates hypoattenuation with loss of gray-white differentiation in the left middle cerebral artery territory (black circle). DWI (B) and corresponding ADC

(C) confirm acute left MCA territory infarct (white circle). MRA (D) demonstrates focal left MCA M2/M3 occlusion (arrow). She was found to be positive for Lupus anticoagulant.

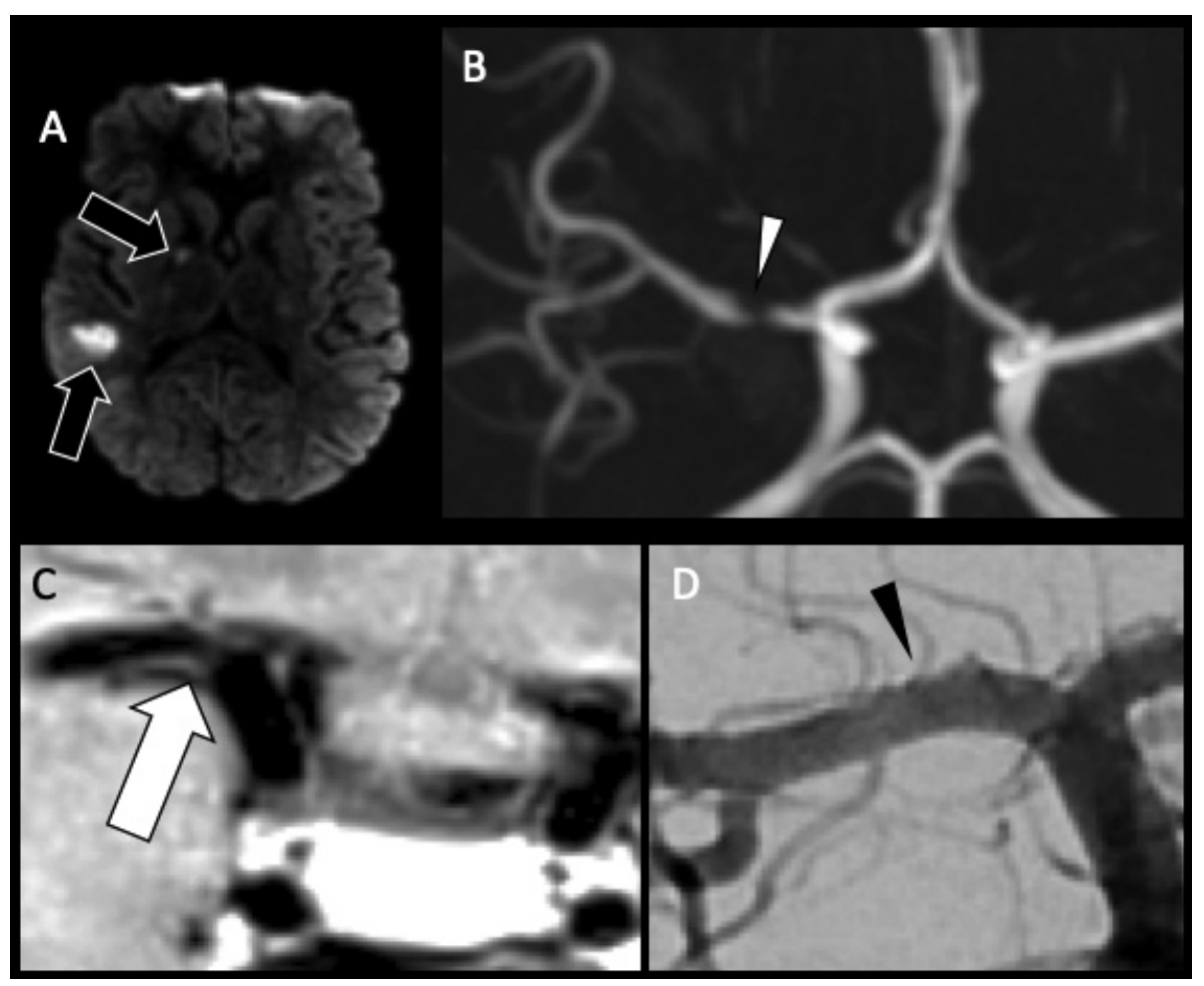

Figure 5. A 13-year-old previously healthy female who presented with new left-sided facial weakness. Diffusion weighted image (A) demonstrate acute infarcts in the right middle cerebral artery (MCA) territory (black arrows). Time-of-Flight MRA (B) shows stenosis of the proximal right M1 MCA segment (white arrowhead). Vessel wall imaging (C) demonstrates a cuff of enhancement at the stenosis (white arrow). Digital subtraction angiography (D) demonstrates a focal arterial irregularity and banding (black arrowhead) resulting in mild stenosis, compatible with focal arteriopathy of a likely inflammatory nature. 
further infarctions $(23,24)$. Outcome is better in patients in whom the arteriopathy stabilizes or improves than in those in whom it progresses, with a high risk of recurrent stroke in the latter population, approaching $25 \%$ within 1 year $(17,24)$. Some genetic arteriopathies have unique imaging appearances, such as ACTA2 mutation, which demonstrates dilation of the proximal internal carotid arteries, occlusion or narrowing of the distal internal carotid arteries, straight "broomsticklike" arteries of the circle of Willis, and absence of lenticulostriate collaterals (Figure 6) (34).

ASL can identify areas of reduced or increased perfusion, helping to differentiate lesions causing stroke or stroke symptoms from mimics $(17,23,95,96)$. The arterial transit time of blood from the labeling plane to the brain is age-dependent and therefore multi-post-label delay or age-specific labeling protocols should be employed. If the post-label delay is too short, perfusion is overestimated in proximal large vessel regions and underestimated in distant brain tissue. These socalled "arterial transit artifacts" can be used to identify focally delayed perfusion in stroke imaging and are tentatively associated with positive outcome, possibly related to collateral flow when occurring more distally (97).

Perfusion imaging (DSC) is useful to identify regions of relative ischemia that are at risk for infarction in moyamoya syndrome and to assess changes in perfusion after therapy. Increased capillary mean transit times and macrovascular delays (e.g., time-to-maxima) may be the result of arterial stenoses or the development of moyamoya collateral vessels (Figure 7) (98). An increase in mean transit time associated with reduced cerebral blood volume or with a lack of increase in cerebral blood volume after administration of intravenous acetazolamide is more suggestive of tissue at risk; although, in the non-acute setting, benign, compensated oligemic delays cannot be discriminated from regions of severe hemodynamic stress with exhausted cerebrovascular reserve, and in this

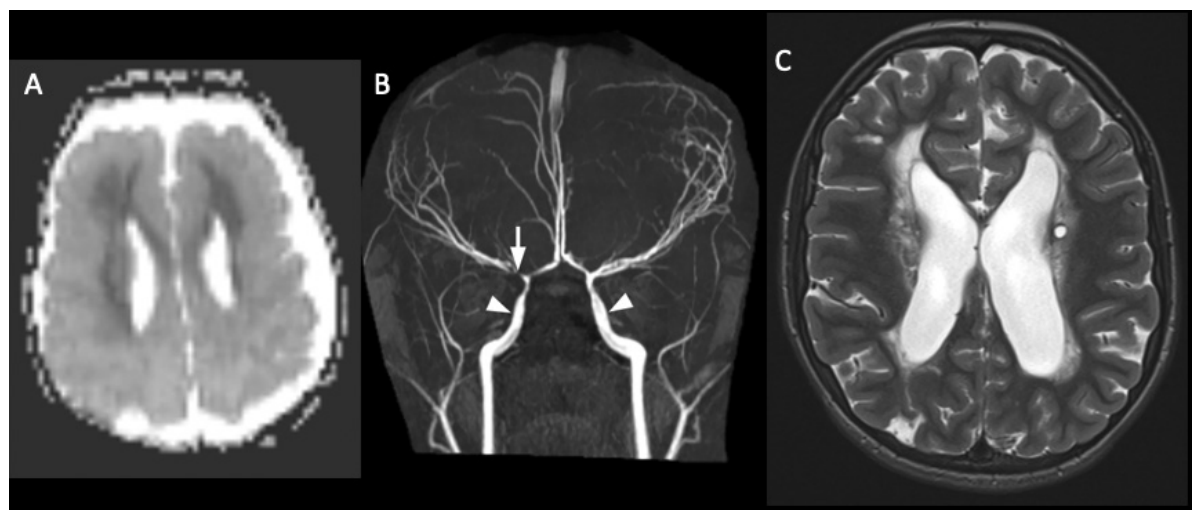

Figure 6. ACTA2 Mutation. Axial ADC (A) demonstrates reduced diffusivity in the periventricular white matter, compatible with acute infarct. 3D Time-of-Flight MRA (B) shows enlargement of the internal carotid arteries (arrowheads) with narrowing of the distal internal carotid arteries (arrow). Follow-up axial T2-weighted image (C) shows evolution of the infarct to cystic encephalomalacia. Case courtesy of Dr. Tamara Feygin, Department of Radiology, Children's Hospital of Philadelphia. 


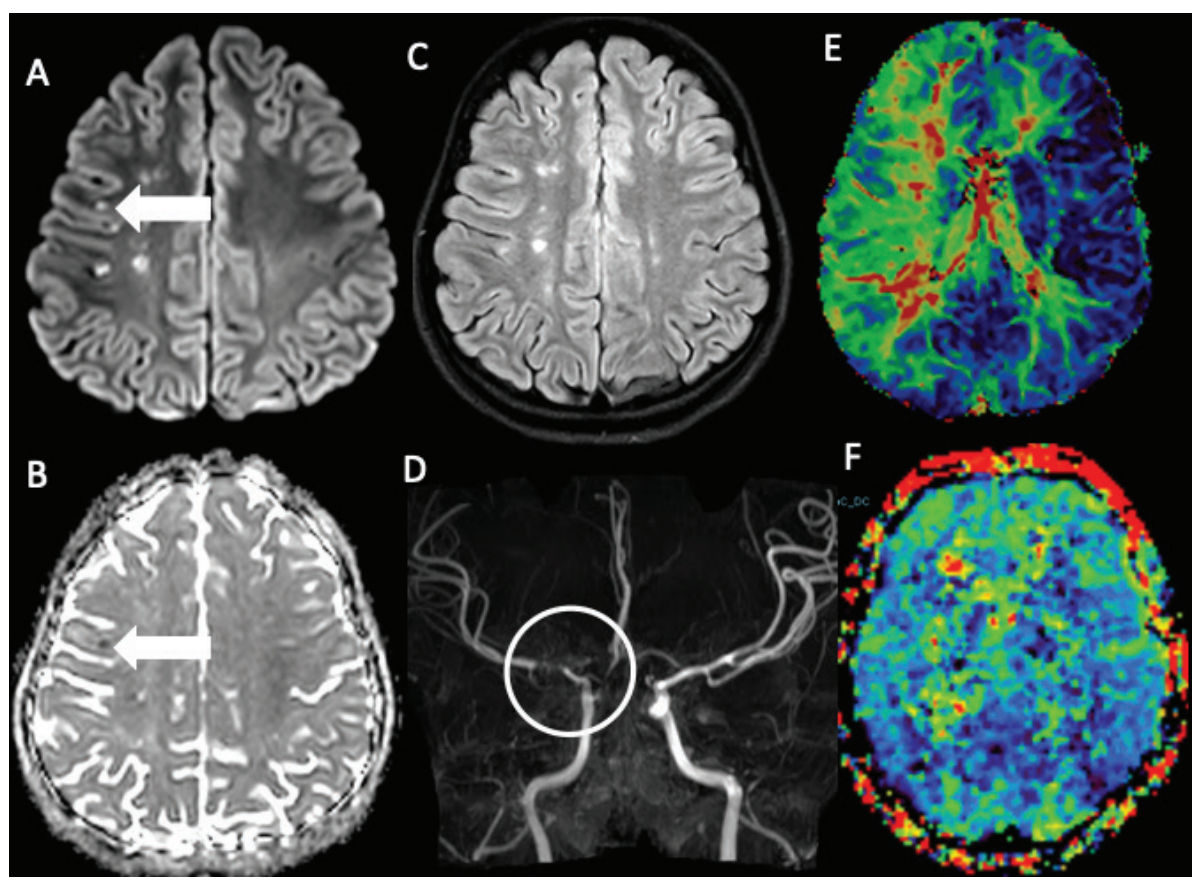

Figure 7. A 17-year-old female who presented with an episode of left facial droop and difficulty speaking. DWI (A) with corresponding ADC (B) and FLAIR (C) MR images demonstrate an acute infarct (arrow) in the left frontal lobe with additional remote infarcts in the bilateral frontoparietal white matter, more on the right than the left. MRA (D) demonstrates occlusion of the right ICA terminus and proximal right ACA and MCA with associated collaterals (circle). DSC perfusion mean transit time (MTT) map (E) demonstrates prolonged MTT in the right middle cerebral artery territory. MTT perfusion map after encephaloduroarteriosynangiosis (F) demonstrates improved, now symmetric transit times between cerebral hemispheres.

setting, cerebrovascular reactivity or direct oximetry may be required for meaningful prognostication (99).

\section{Hemorrhagic stroke}

Vascular malformations, primarily arteriovenous malformations (AVMs), cavernous malformations, and aneurysms, are the most common causes of pediatric hemorrhagic stroke $(100,101)$. CT is often the first neuroimaging performed because of its sensitivity for detection of hemorrhage, at which time CTA can be performed to assess for underlying vascular malformations or aneurysm. Importantly, CTA does not accurately discriminate venous lumenal enhancement of a physiologic nature from that arising across arteriovenous shunts, and CT should be considered of relatively limited sensitivity and specificity for detection of small shunt malformations. In a stable child, MRI brain with DWI, SWI or GRE, FLAIR, MRA, and MRV can diagnose hemorrhage, differentiate hemorrhagic transformation of arterial or venous infarction from primary hemorrhage, and 
evaluate the brain parenchyma for an underlying mass or vascular malformation. Time-of-flight techniques, particularly without exogenous gadolinium, generally highlight brisk arteriographic flow and consequently suppress slow-flowing venous blood; consequently, extensive venographic signal may raise suspicion for shunting of arterial flow but must be discriminated from potential technical sources of venographic enhancement. ASL may be useful for detecting arteriovenous shunting in an AVM, owing to the nearly complete extraction of tagged water across the blood brain barrier and T1-mediated tag decay, which together leave venous signal unlikely in conventional tagging schemes without arteriovenous shunting (102). Catheter angiography may be considered if no lesion is identified on initial imaging to assess for small vascular malformations. If no vascular malformation is identified, repeat neuroimaging should be obtained after the hematoma has resolved, as small vascular lesions can be compressed by the hematoma (103).

\section{Venous sinus thrombosis and venous infarct}

Venous thrombosis is a common cause of spontaneous cerebral hemorrhage, both intraparenchymal and, rarely, epidural, with nearly $70 \%$ of pediatric venous infarcts becoming hemorrhagic (Figure 8) $(104,105)$. Parasagittal injuries are seen with superior sagittal sinus thrombosis, temporal lobe hematomas with transverse sinus thrombosis, and thalamic hemorrhage with vein of Galen/straight sinus thrombosis.

In infants and children, MRI is the imaging modality of choice. Routine T1and T2-weighted images should be obtained (and FLAIR in older infants and in children), in addition to DWI, GRE or SWI images, and MRV. Acute ( $<7$ days old) thrombus exhibits low signal intensity due to the presence of deoxygenated hemoglobin beginning quickly following its development, often with apparent expansion of the affected sinus on GRE and reduced diffusivity (106). If the thrombosis is subacute (between 6 and 15 days), Tl-weighted images show high signal intensity of the clot, potentially with persistently reduced diffusion during the intracellular stages of hemoglobin breakdown (107).

$\mathrm{CT}$ venography, showing thrombi as hypodense areas within the affected venous structure ("empty delta sign" with thrombosis of the superior sagittal sinus or other veins captured in cross section), is very sensitive and specific for the diagnosis of dural sinus thrombosis, but of limited diagnostic value for diagnosing cortical vein thrombosis and often avoided due to the utilization ionizing radiation (108). Multiple MRI techniques have been developed to detect venous thromboses, including time-of-flight and phase contrast venography, both of which are performed without the use of gadolinium, as well as contrast-enhanced techniques. With DSA as reference standard, contrast-enhanced MRI was shown to be more accurate for diagnosing cerebral sinus thrombosis than noncontrastenhanced flow-related and native contrast MR sequences, likely due to superior performance where flow-related enhancement is diminished due to slow flow or flow parallel to the imaging plane $(109,110)$.

On CT, venous infarcts are usually poorly delimited, hypodense, or mixedattenuation, with the low attenuation likely related to cerebral edema and high attenuation hemorrhage (20). The thrombosed vein may be seen overlying 


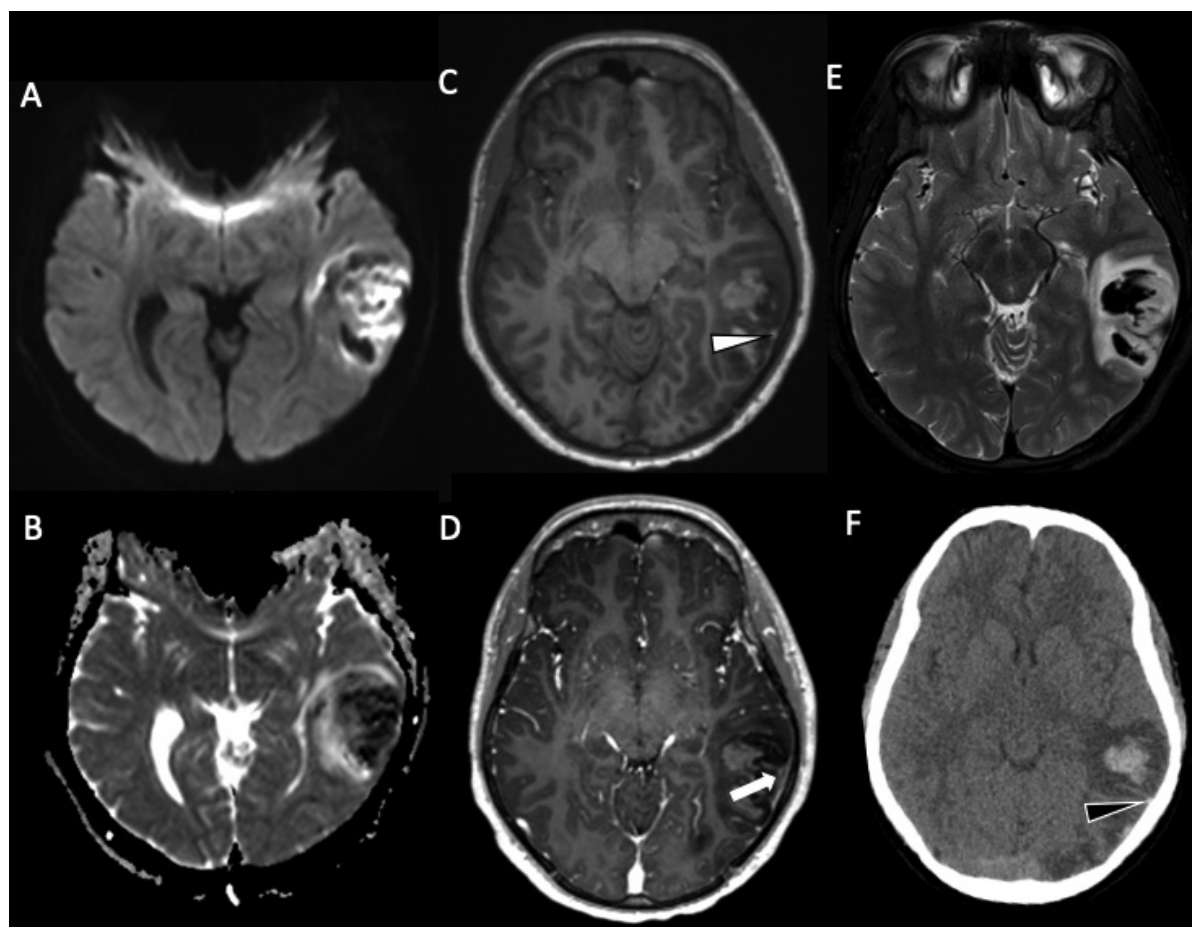

Figure 8. An 18-year-old male who presented with intractable headache found to have left vein of Labbe thrombosis and hemorrhagic venous infarct. DWI (A) and associated ADC (B) demonstrates associated vasogenic and cytotoxic edema. Noncontract T1-weighted image (C) shows high signal within the left vein of Labbe (white arrowhead) with associated filling defect on contrast enhanced study (white arrow) (D). No underlying vascular malformation or mass was identified. T2-weighted MRI (E) demonstrates a left posterior temporal hematoma with associated edema. Noncontrast axial CT image (F) demonstrates parenchymal hemorrhage with hyperdensity within the vein of Labbe (black arrow).

the infarction as a curvilinear region of high attenuation. On MR, early venous infarcts may demonstrate high signal on T2-weighted sequences in characteristic regions (most commonly frontoparietal parasagittal and temporal). SWI can identify the thrombosis in the superficial and/or deep venous systems. DWI may show reduced, normal, increased, or a mixture of diffusivity in areas of venous infarction, and potentially reduced diffusivity of the pathologic vessel itself in the acute phases of thrombosis as noted above. Venous sinus occlusion initially reduces venous outflow, with resultant vasogenic edema, which causes increased diffusion (111). If adequate collateral venous outflow is not established, venous infarction will occur, resulting in cytotoxic edema. The paramagnetic effects of blood products, often present in venous infarcts (up to 70\%), may also contribute to this heterogeneity of diffusion characteristics in the tissues, and may be accompanied by phase accrual and signal decay within the deep and superficial venous circulation on the filtered signal phase maps of susceptibility weighted images, respectively. Hemorrhage in such cases may vary from large subcortical hematomas to petechial hemorrhages within edematous brain parenchyma $(52,112)$. 


\section{STROKE MIMICS}

The diagnosis of stroke is often difficult in infants and children due to the nonspecific localizing signs of stroke, such as lateralized weakness after seizure or ataxia, are often overlooked (67). In a study of 209 children with acute AIS, 70\% of children reached a hospital within six hours of stroke symptom onset, but only $20 \%$ were diagnosed with stroke within six hours and stroke was not suspected in more than $62 \%$ of children at initial presentation (66). Other serious neurologic diagnoses can present similarly, including posterior reversible leukoencephalopathy, epilepsy, intracranial infection or inflammation, focal lesions (i.e., tumors), complicated migraine syndromes, and drug toxicity (Figure 9) $(113,114)$.

\section{TREATMENT}

Although observational studies and expert consensus support the use of intravenous tissue plasminogen activator (tPA) in pediatric patients, the safety and efficacy have not been validated in prospective trials (115-117). The Thrombolysis in Pediatric Stroke (TIPS) Trial was a phase I multicenter study evaluating the safety of tPA in childhood stroke but was closed early due to low enrollment (118). Intravenous tPA administration is currently given within 4.5 hours of documented onset in children. In children with sickle cell disease, the mechanism of stroke is different and treatment is directed toward reducing the proportion of sickled red cells and reestablishing cerebral vascular patency. Exchange transfusion should be performed urgently to decrease the fraction of $\mathrm{HbS}$ to below 30\%. Transfusion may also be appropriate in the setting of acute anemia. Endovascular therapies, including intraarterial tPA and mechanical thrombectomy, are increasingly used for acute revascularization in adults with ischemic stroke and are used in children

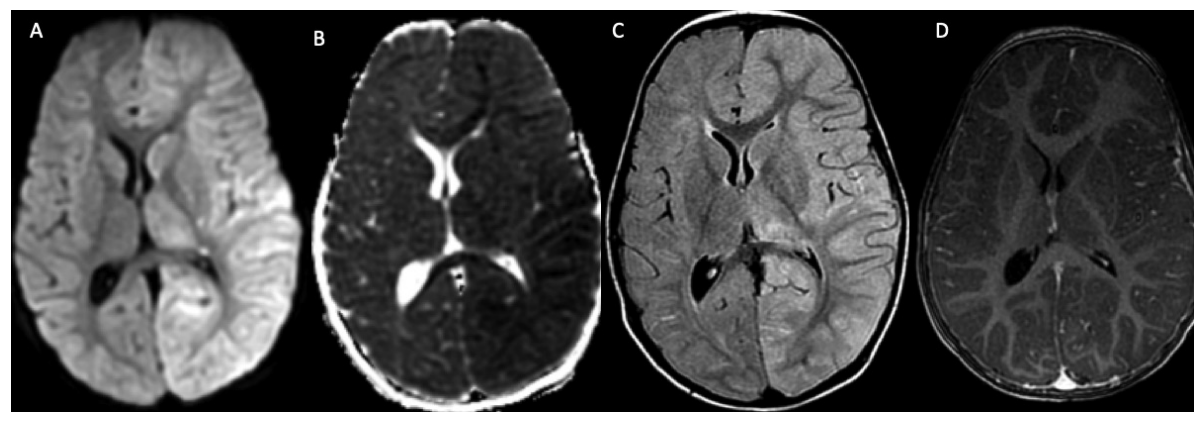

Figure 9. A 21-month-old Female who presented with headache and right-sided weakness. DWI (A) and corresponding ADC map (B) demonstrate diffusion hyperintensity throughout the left cerebral hemisphere, some of which is cytotoxic and some vasogenic edema. FLAIR (C) demonstrates edema in the left cerebral hemisphere with gyral swelling. No associated enhancement was noted on post-contrast imaging (D). The patient was diagnosed with familial hemiplegic migraine and found to have an underlying CACNA1A mutation. 
on a case-by-case basis, although evidence is growing for its efficacy (119). For CSVT, anticoagulation is used in patients who do not have significant intracranial hemorrhage. About 30\% of CSVTs propagate, with $40 \%$ of these developing venous infarctions, thus in children with CSVT and milder hemorrhage, the benefits of preventing further infarction and hemorrhage by anticoagulation may debatably outweigh the risks of worsening the existing hemorrhage (120). Approximately $40-50 \%$ of infants and children affected by CSVT are neurologically normal after approximately two years $(52,55)$.

\section{PROGNOSIS}

More than $75 \%$ of children will suffer long-term neurological deficits after AIS and 10\% will die, with 19\% recurrence at five years (3, 4, 121-123). Long-term prognosis of children with focal infarctions and no underlying disorder varies with the location of the infarction and the age of the patient at the time of the injury (124). Poor motor outcome is associated with basal ganglia involvement, while seizures, poor cognition, and delayed development are associated with cortical involvement $(24,125)$. Larger infarct volumes or infarctions involving eloquent regions show more substantial residual deficits $(123,126)$. Among children with infarcts of similar size or location, younger patients typically have smaller clinical deficits (124). The greater neuroplasticity of the brain in childhood may facilitate many functions normally performed by the injured brain regions being assumed by spared functional loci (123). When epilepsy develops, however, cognitive recovery may be impaired (123).

\section{CONCLUSION}

Stroke in the pediatric period is increasingly being recognized as an important cause of morbidity and mortality. Understanding the unique presentation and etiologies is important for accurate and timely diagnosis. The use of appropriate neuroimaging is essential for making the correct diagnosis, directing treatment, excluding alternative diagnoses, and determining prognosis. As the understanding of the mechanism of pediatric stroke progresses and treatments improve, neuroimaging will continue to be an essential component of patient management.

Acknowledgement: We would like to thank Dr. Tamara Feygin for providing cases and for contributing valuable insights to the content herein.

Conflict of interest: Dr. Dehkharghani reports unpaid scientific collaborations and the receipt of travel and research support form iSchemaView, as well as scientific consulting with Regeneron, both unrelated to the content herein. Dr. Dehkharghani receives grant funding from undisclosed sources paid to his institution, also in work unrelated to the content of this chapter. The authors declare no other potential conflicts of interest with respect to research, authorship and/or publication of this article. 
Copyright and permission statement: The authors confirm that the materials included in this chapter do not violate copyright laws. Where relevant, appropriate permissions have been obtained from the original copyright holder(s), and all original sources have been appropriately acknowledged or referenced.

\section{REFERENCES}

1. Steinlin M. A clinical approach to arterial ischemic childhood stroke: increasing knowledge over the last decade. Neuropediatrics. 2012;43(1):1-9. https://doi.org/10.1055/s-0032-1307449

2. Kirton A, deVeber G. Paediatric stroke: pressing issues and promising directions. Lancet Neurol. 2015;14(1):92-102. https://doi.org/10.1016/S1474-4422(14)70227-3

3. Fullerton HJ, Chetkovich DM, Wu YW, Smith WS, Johnston SC. Deaths from stroke in US children, 1979 to 1998. Neurology. 2002;59(1):34-9. https://doi.org/10.1212/WNL.59.1.34

4. Fullerton HJ, Wu YW, Zhao S, Johnston SC. Risk of stroke in children: ethnic and gender disparities. Neurology. 2003;61(2):189-94. https://doi.org/10.1212/01.WNL.0000078894.79866.95

5. Laugesaar R, Kolk A, Tomberg T, Metsvaht T, Lintrop M, Varendi H, et al. Acutely and retrospectively diagnosed perinatal stroke: a population-based study. Stroke. 2007;38(8):2234-40. https://doi. org/10.1161/STROKEAHA.107.483743

6. Lee J, Croen LA, Backstrand KH, Yoshida CK, Henning LH, Lindan C, et al. Maternal and infant characteristics associated with perinatal arterial stroke in the infant. JAMA. 2005;293(6):723-9. https:// doi.org/10.1001/jama.293.6.723

7. Giroud M, Lemesle M, Gouyon JB, Nivelon JL, Milan C, Dumas R. Cerebrovascular disease in children under 16 years of age in the city of Dijon, France: a study of incidence and clinical features from 1985 to 1993. J Clin Epidemiol. 1995;48(11):1343-8. https://doi. org/10.1016/0895-4356(95)00039-9

8. Agrawal N, Johnston SC, Wu YW, Sidney S, Fullerton HJ. Imaging data reveal a higher pediatric stroke incidence than prior US estimates. Stroke. 2009;40(11):3415-21. https://doi.org/10.1161/ STROKEAHA.109.564633

9. Raju TN, Nelson KB, Ferriero D, Lynch JK, Participants N-NPSW. Ischemic perinatal stroke: summary of a workshop sponsored by the National Institute of Child Health and Human Development and the National Institute of Neurological Disorders and Stroke. Pediatrics. 2007;120(3):609-16. https://doi. org/10.1542/peds.2007-0336

10. Goncalves FG, Alves C, Heuer B, Peterson J, Viaene AN, Reis Teixeira S, et al. Primary Mitochondrial Disorders of the Pediatric Central Nervous System: Neuroimaging Findings. Radiographics. 2020;40(7):2042-67. https://doi.org/10.1148/rg.2020200052

11. Heinz ER, Provenzale JM. Imaging findings in neonatal hypoxia: a practical review. AJR Am J Roentgenol. 2009;192(1):41-7. https://doi.org/10.2214/AJR.08.1321

12. Lehman LL, Watson CG, Kapur K, Danehy AR, Rivkin MJ. Predictors of Stroke After Transient Ischemic Attack in Children. Stroke. 2016;47(1):88-93. https://doi.org/10.1161/STROKEAHA.115.009904

13. Boulouis G, Stricker S, Benichi S, Hak JF, Gariel F, Alias Q, et al. Etiology of intracerebral hemorrhage in children: cohort study, systematic review, and meta-analysis. J Neurosurg Pediatr. 2021:1-7.

14. Chabrier S, Husson B, Dinomais M, Landrieu P, Nguyen The Tich S. New insights (and new interrogations) in perinatal arterial ischemic stroke. Thromb Res. 2011;127(1):13-22. https://doi. org/10.1016/j.thromres.2010.10.003

15. Lee YY, Lin KL, Wang HS, Chou ML, Hung PC, Hsieh MY, et al. Risk factors and outcomes of childhood ischemic stroke in Taiwan. Brain Dev. 2008;30(1):14-9. https://doi.org/10.1016/j. braindev.2007.05.002

16. Fullerton HJ, Hills NK, Elkind MS, Dowling MM, Wintermark M, Glaser CA, et al. Infection, vaccination, and childhood arterial ischemic stroke: Results of the VIPS study. Neurology. 2015;85(17):1459-66. https://doi.org/10.1212/WNL.0000000000002065 
17. Fullerton HJ, Wintermark M, Hills NK, Dowling MM, Tan M, Rafay MF, et al. Risk of Recurrent Arterial Ischemic Stroke in Childhood: A Prospective International Study. Stroke. 2016;47(1):53-9. https://doi.org/10.1161/STROKEAHA.115.011173

18. Ganesan V, Prengler M, McShane MA, Wade AM, Kirkham FJ. Investigation of risk factors in children with arterial ischemic stroke. Ann Neurol. 2003;53(2):167-73. https://doi.org/10.1002/ana.10423

19. Lynch JK, Han CJ, Nee LE, Nelson KB. Prothrombotic factors in children with stroke or porencephaly. Pediatrics. 2005;116(2):447-53. https://doi.org/10.1542/peds.2004-1905

20. Barkovich AJ. Pediatric neuroimaging. New York: Raven Press; 1990. xi, 355 p. p.

21. Fullerton HJ, Elkind MS, Barkovich AJ, Glaser C, Glidden D, Hills NK, et al. The vascular effects of infection in Pediatric Stroke (VIPS) Study. J Child Neurol. 2011;26(9):1101-10. https://doi. org/10.1177/0883073811408089

22. Mineyko A, Kirton A. Mechanisms of pediatric cerebral arteriopathy: an inflammatory debate. Pediatr Neurol. 2013;48(1):14-23. https://doi.org/10.1016/j.pediatrneurol.2012.06.021

23. Wintermark M, Hills NK, deVeber GA, Barkovich AJ, Elkind MS, Sear K, et al. Arteriopathy diagnosis in childhood arterial ischemic stroke: results of the vascular effects of infection in pediatric stroke study. Stroke. 2014;45(12):3597-605. https://doi.org/10.1161/STROKEAHA.114.007404

24. Braun KP, Bulder MM, Chabrier S, Kirkham FJ, Uiterwaal CS, Tardieu M, et al. The course and outcome of unilateral intracranial arteriopathy in 79 children with ischaemic stroke. Brain. 2009;132(Pt 2): 544-57. https://doi.org/10.1093/brain/awn313

25. Bernard TJ, Manco-Johnson MJ, Lo W, MacKay MT, Ganesan V, DeVeber G, et al. Towards a consensusbased classification of childhood arterial ischemic stroke. Stroke. 2012;43(2):371-7. https://doi. org/10.1161/STROKEAHA.111.624585

26. Sebire G, Fullerton H, Riou E, deVeber G. Toward the definition of cerebral arteriopathies of childhood. Curr Opin Pediatr. 2004;16(6):617-22. https://doi.org/10.1097/01.mop.0000144441.29899.20

27. Hagberg H, Mallard C, Ferriero DM, Vannucci SJ, Levison SW, Vexler ZS, et al. The role of inflammation in perinatal brain injury. Nat Rev Neurol. 2015;11(4):192-208. https://doi.org/10.1038/ nrneurol.2015.13

28. Lanthier S, Armstrong D, Domi T, deVeber G. Post-varicella arteriopathy of childhood: natural history of vascular stenosis. Neurology. 2005;64(4):660-3. https://doi.org/10.1212/01. WNL.0000151851.66154.27

29. Kamholz J, Tremblay G. Chickenpox with delayed contralateral hemiparesis caused by cerebral angiitis. Ann Neurol. 1985;18(3):358-60. https://doi.org/10.1002/ana.410180317

30. Wintermark M, Hills NK, DeVeber GA, Barkovich AJ, Bernard TJ, Friedman NR, et al. Clinical and Imaging Characteristics of Arteriopathy Subtypes in Children with Arterial Ischemic Stroke: Results of the VIPS Study. AJNR Am J Neuroradiol. 2017;38(11):2172-9. https://doi.org/10.3174/ ajnr.A5376

31. Appavu B, Deng D, Dowling MM, Garg S, Mangum T, Boerwinkle V, et al. Arteritis and Large Vessel Occlusive Strokes in Children Following COVID-19 Infection. Pediatrics. 2020. https://doi. org/10.1542/peds.2020-023440

32. Lindan CE, Mankad K, Ram D, Kociolek LK, Silvera VM, Boddaert N, et al. Neuroimaging manifestations in children with SARS-CoV-2 infection: a multinational, multicentre collaborative study. Lancet Child Adolesc Health. 2020. https://doi.org/10.1016/S2352-4642(20)30362-X

33. Beslow LA, Linds AB, Fox CK, Kossorotoff M, Zuniga Zambrano YC, Hernandez-Chavez M, et al. Pediatric Ischemic Stroke: An Infrequent Complication of SARS-CoV-2. Ann Neurol. 2020. https:// doi.org/10.1002/ana.25991

34. D'Arco F, Alves CA, Raybaud C, Chong WKK, Ishak GE, Ramji S, et al. Expanding the Distinctive Neuroimaging Phenotype of ACTA2 Mutations. AJNR Am J Neuroradiol. 2018;39(11):2126-31. https://doi.org/10.3174/ajnr.A5823

35. deVeber G, Monagle P, Chan A, MacGregor D, Curtis R, Lee S, et al. Prothrombotic disorders in infants and children with cerebral thromboembolism. Arch Neurol. 1998;55(12):1539-43. https:// doi.org/10.1001/archneur.55.12.1539

36. Mercuri E, Cowan F, Gupte G, Manning R, Laffan M, Rutherford M, et al. Prothrombotic disorders and abnormal neurodevelopmental outcome in infants with neonatal cerebral infarction. Pediatrics. 2001;107(6):1400-4. https://doi.org/10.1542/peds.107.6.1400 
37. Steinlin M, Pfister I, Pavlovic J, Everts R, Boltshauser E, Capone Mori A, et al. The first three years of the Swiss Neuropaediatric Stroke Registry (SNPSR): a population-based study of incidence, symptoms and risk factors. Neuropediatrics. 2005;36(2):90-7. https://doi. org/10.1055/s-2005-837658

38. Golomb MR, MacGregor DL, Domi T, Armstrong DC, McCrindle BW, Mayank S, et al. Presumed pre- or perinatal arterial ischemic stroke: risk factors and outcomes. Ann Neurol. 2001;50(2):163-8. https://doi.org/10.1002/ana.1078

39. Singhal NS, Hills NK, Sidney S, Fullerton HJ. Role of trauma and infection in childhood hemorrhagic stroke due to vascular lesions. Neurology. 2013;81(6):581-4. https://doi.org/10.1212/ WNL.0b013e31829e6f5f

40. Hills NK, Johnston SC, Sidney S, Zielinski BA, Fullerton HJ. Recent trauma and acute infection as risk factors for childhood arterial ischemic stroke. Ann Neurol. 2012;72(6):850-8. https://doi. org/10.1002/ana.23688

41. Amlie-Lefond C, Bernard TJ, Sebire G, Friedman NR, Heyer GL, Lerner NB, et al. Predictors of cerebral arteriopathy in children with arterial ischemic stroke: results of the International Pediatric Stroke Study. Circulation. 2009;119(10):1417-23. https://doi.org/10.1161/CIRCULATIONAHA.108.806307

42. Lynch JK, Hirtz DG, DeVeber G, Nelson KB. Report of the National Institute of Neurological Disorders and Stroke workshop on perinatal and childhood stroke. Pediatrics. 2002;109(1):116-23. https://doi. org/10.1542/peds.109.1.116

43. Gould DB, Phalan FC, Breedveld GJ, van Mil SE, Smith RS, Schimenti JC, et al. Mutations in Col4al cause perinatal cerebral hemorrhage and porencephaly. Science. 2005;308(5725):1167-71. https:// doi.org/10.1126/science.1109418

44. Mochida GH, Ganesh VS, Felie JM, Gleason D, Hill RS, Clapham KR, et al. A homozygous mutation in the tight-junction protein JAM3 causes hemorrhagic destruction of the brain, subependymal calcification, and congenital cataracts. Am J Hum Genet. 2010;87(6):882-9. https://doi.org/10.1016/j. ajhg.2010.10.026

45. Akawi NA, Canpolat FE, White SM, Quilis-Esquerra J, Morales Sanchez M, Gamundi MJ, et al. Delineation of the clinical, molecular and cellular aspects of novel JAM3 mutations underlying the autosomal recessive hemorrhagic destruction of the brain, subependymal calcification, and congenital cataracts. Hum Mutat. 2013;34(3):498-505. https://doi.org/10.1002/humu.22263

46. van der Knaap MS, Smit LM, Barkhof F, Pijnenburg YA, Zweegman S, Niessen HW, et al. Neonatal porencephaly and adult stroke related to mutations in collagen IV Al. Ann Neurol. 2006;59(3): 504-11. https://doi.org/10.1002/ana.20715

47. de Vries LS, Koopman C, Groenendaal F, Van Schooneveld M, Verheijen FW, Verbeek E, et al. COL4A1 mutation in two preterm siblings with antenatal onset of parenchymal hemorrhage. Ann Neurol. 2009;65(1):12-8. https://doi.org/10.1002/ana.21525

48. Livingston J, Doherty D, Orcesi S, Tonduti D, Piechiecchio A, La Piana R, et al. COL4Al mutations associated with a characteristic pattern of intracranial calcification. Neuropediatrics. 2011;42(6): 227-33. https://doi.org/10.1055/s-0031-1295493

49. Yoneda Y, Haginoya K, Kato M, Osaka H, Yokochi K, Arai H, et al. Phenotypic spectrum of COL4Al mutations: porencephaly to schizencephaly. Ann Neurol. 2013;73(1):48-57. https://doi.org/10.1002/ ana. 23736

50. Renard D, Mine M, Pipiras E, Labauge P, Delahaye A, Benzacken B, et al. Cerebral small-vessel disease associated with COL4A1 and COL4A2 gene duplications. Neurology. 2014;83(11):1029-31. https:// doi.org/10.1212/WNL.0000000000000769

51. Meuwissen ME, de Vries LS, Verbeek HA, Lequin MH, Govaert PP, Schot R, et al. Sporadic COL4Al mutations with extensive prenatal porencephaly resembling hydranencephaly. Neurology. 2011;76(9):844-6. https://doi.org/10.1212/WNL.0b013e31820e7751

52. deVeber G, Andrew M, Adams C, Bjornson B, Booth F, Buckley DJ, et al. Cerebral sinovenous thrombosis in children. N Engl J Med. 2001;345(6):417-23. https://doi.org/10.1056/ NEJM200108093450604

53. Heller C, Heinecke A, Junker R, Knofler R, Kosch A, Kurnik K, et al. Cerebral venous thrombosis in children: a multifactorial origin. Circulation. 2003;108(11):1362-7. https://doi.org/10.1161/01. CIR.0000087598.05977.45 
54. Lynch JK, Nelson KB. Epidemiology of perinatal stroke. Curr Opin Pediatr. 2001;13(6):499-505. https://doi.org/10.1097/00008480-200112000-00002

55. Sebire G, Tabarki B, Saunders DE, Leroy I, Liesner R, Saint-Martin C, et al. Cerebral venous sinus thrombosis in children: risk factors, presentation, diagnosis and outcome. Brain. 2005;128(Pt 3): 477-89. https://doi.org/10.1093/brain/awh412

56. Teksam M, Moharir M, Deveber G, Shroff M. Frequency and topographic distribution of brain lesions in pediatric cerebral venous thrombosis. AJNR Am J Neuroradiol. 2008;29(10):1961-5. https://doi. org/10.3174/ajnr.A1246

57. Huisman TA, Holzmann D, Martin E, Willi UV. Cerebral venous thrombosis in childhood. Eur Radiol. 2001;11(9):1760-5. https://doi.org/10.1007/s003300100822

58. Israels SJ, Seshia SS. Childhood stroke associated with protein C or S deficiency. J Pediatr. 1987;111(4):562-4. https://doi.org/10.1016/S0022-3476(87)80122-1

59. Zoller B, Dahlback B. Linkage between inherited resistance to activated protein C and factor V gene mutation in venous thrombosis. Lancet. 1994;343(8912):1536-8. https://doi.org/10.1016/ S0140-6736(94)92940-8

60. Brey RL, Coull BM. Cerebral venous thrombosis. Role of activated protein C resistance and factor V gene mutation. Stroke. 1996;27(10):1719-20. https://doi.org/10.1161/01.STR.27.10.1719

61. Gobel U. Inherited or acquired disorders of blood coagulation in children with neurovascular complications. Neuropediatrics. 1994;25(1):4-7. https://doi.org/10.1055/s-2008-1071573

62. van Kuijck MA, Rotteveel JJ, van Oostrom CG, Novakova I. Neurological complications in children with protein C deficiency. Neuropediatrics. 1994;25(1):16-9. https://doi.org/10.1055/s-2008-1071575

63. Nowak-Gottl U, Strater R, Heinecke A, Junker R, Koch HG, Schuierer G, et al. Lipoprotein (a) and genetic polymorphisms of clotting factor $\mathrm{V}$, prothrombin, and methylenetetrahydrofolate reductase are risk factors of spontaneous ischemic stroke in childhood. Blood. 1999;94(11):3678-82. https:// doi.org/10.1182/blood.V94.11.3678

64. Schoning M, Klein R, Krageloh-Mann I, Falck M, Bien S, Berg PA, et al. Antiphospholipid antibodies in cerebrovascular ischemia and stroke in childhood. Neuropediatrics. 1994;25(1):8-14. https://doi. org/10.1055/s-2008-1071574

65. Angelini L, Zibordi F, Zorzi G, Nardocci N, Caporali R, Ravelli A, et al. Neurological disorders, other than stroke, associated with antiphospholipid antibodies in childhood. Neuropediatrics. 1996;27(3):149-53. https://doi.org/10.1055/s-2007-973766

66. Rafay MF, Pontigon AM, Chiang J, Adams M, Jarvis DA, Silver F, et al. Delay to diagnosis in acute pediatric arterial ischemic stroke. Stroke. 2009;40(1):58-64. https://doi.org/10.1161/ STROKEAHA.108.519066

67. Mirsky DM, Beslow LA, Amlie-Lefond C, Krishnan P, Laughlin S, Lee S, et al. Pathways for Neuroimaging of Childhood Stroke. Pediatr Neurol. 2017;69:11-23. https://doi.org/10.1016/j. pediatrneurol.2016.12.004

68. Hales PW, Kawadler JM, Aylett SE, Kirkham FJ, Clark CA. Arterial spin labeling characterization of cerebral perfusion during normal maturation from late childhood into adulthood: normal 'reference range' values and their use in clinical studies. J Cereb Blood Flow Metab. 2014;34(5):776-84. https:// doi.org/10.1038/jcbfm.2014.17

69. Stence NV, Pabst LL, Hollatz AL, Mirsky DM, Herson PS, Poisson S, et al. Predicting Progression of Intracranial Arteriopathies in Childhood Stroke With Vessel Wall Imaging. Stroke. 2017;48(8): 2274-7. https://doi.org/10.1161/STROKEAHA.117.017922

70. Husson B, Lasjaunias P. Radiological approach to disorders of arterial brain vessels associated with childhood arterial stroke-a comparison between MRA and contrast angiography. Pediatr Radiol. 2004;34(1):10-5. https://doi.org/10.1007/s00247-003-1109-0

71. Yun TJ, Cheon JE, Na DG, Kim WS, Kim IO, Chang KH, et al. Childhood moyamoya disease: quantitative evaluation of perfusion MR imaging--correlation with clinical outcome after revascularization surgery. Radiology. 2009;251(1):216-23. https://doi.org/10.1148/radiol.2511080654

72. Ganesan V, Chong WK, Cox TC, Chawda SJ, Prengler M, Kirkham FJ. Posterior circulation stroke in childhood: risk factors and recurrence. Neurology. 2002;59(10):1552-6. https://doi.org/10.1212/01. WNL.0000033092.87560.1A 
73. Rosa M, De Lucia S, Rinaldi VE, Le Gal J, Desmarest M, Veropalumbo C, et al. Paediatric arterial ischemic stroke: acute management, recent advances and remaining issues. Ital J Pediatr. 2015;41:95. https://doi.org/10.1186/s13052-015-0174-y

74. Caplan LR. Migraine and vertebrobasilar ischemia. Neurology. 1991;41(1):55-61. https://doi. org/10.1212/WNL.41.1.55

75. Koo B, Becker LE, Chuang S, Merante F, Robinson BH, MacGregor D, et al. Mitochondrial encephalomyopathy, lactic acidosis, stroke-like episodes (MELAS): clinical, radiological, pathological, and genetic observations. Ann Neurol. 1993;34(1):25-32. https://doi.org/10.1002/ana.410340107

76. Goodfellow JA, Dani K, Stewart W, Santosh C, McLean J, Mulhern S, et al. Mitochondrial myopathy, encephalopathy, lactic acidosis and stroke-like episodes: an important cause of stroke in young people. Postgrad Med J. 2012;88(1040):326-34. https://doi.org/10.1136/ postgradmedj-2011-130326

77. Garg BP, DeMyer WE. Ischemic thalamic infarction in children: clinical presentation, etiology, and outcome. Pediatr Neurol. 1995;13(1):46-9. https://doi.org/10.1016/0887-8994(95)00108-R

78. Lequin MH, Dudink J, Tong KA, Obenaus A. Magnetic resonance imaging in neonatal stroke. Semin Fetal Neonatal Med. 2009;14(5):299-310. https://doi.org/10.1016/j.siny.2009.07.005

79. Nakano S, Iseda T, Kawano H, Yoneyama T, Ikeda T, Wakisaka S. Correlation of early CT signs in the deep middle cerebral artery territories with angiographically confirmed site of arterial occlusion. AJNR Am J Neuroradiol. 2001;22(4):654-9.

80. Allen LM, Hasso AN, Handwerker J, Farid H. Sequence-specific MR imaging findings that are useful in dating ischemic stroke. Radiographics. 2012;32(5):1285-97; discussion 97-9. https://doi. org/10.1148/rg.325115760

81. Cowan FM, Pennock JM, Hanrahan JD, Manji KP, Edwards AD. Early detection of cerebral infarction and hypoxic ischemic encephalopathy in neonates using diffusion-weighted magnetic resonance imaging. Neuropediatrics. 1994;25(4):172-5. https://doi.org/10.1055/s-2008-1073018

82. McKinstry RC, Miller JH, Snyder AZ, Mathur A, Schefft GL, Almli CR, et al. A prospective, longitudinal diffusion tensor imaging study of brain injury in newborns. Neurology. 2002;59(6):824-33. https://doi.org/10.1212/WNL.59.6.824

83. Dudink J, Mercuri E, Al-Nakib L, Govaert P, Counsell SJ, Rutherford MA, et al. Evolution of unilateral perinatal arterial ischemic stroke on conventional and diffusion-weighted MR imaging. AJNR Am J Neuroradiol. 2009;30(5):998-1004. https://doi.org/10.3174/ajnr.A1480

84. Schlaug G, Siewert B, Benfield A, Edelman RR, Warach S. Time course of the apparent diffusion coefficient (ADC) abnormality in human stroke. Neurology. 1997;49(1):113-9. https://doi.org/10.1212/ WNL.49.1.113

85. Dehkharghani S, Andre J. Imaging Approaches to Stroke and Neurovascular Disease. Neurosurgery. 2017;80(5):681-700. https://doi.org/10.1093/neuros/nyw108

86. Krieger DA, Dehkharghani S. Magnetic Resonance Imaging in Ischemic Stroke and Cerebral Venous Thrombosis. Top Magn Reson Imaging. 2015;24(6):331-52. https://doi.org/10.1097/ RMR.0000000000000067

87. Schroder J, Thomalla G. A Critical Review of Alberta Stroke Program Early CT Score for Evaluation of Acute Stroke Imaging. Front Neurol. 2016;7:245. https://doi.org/10.3389/fneur.2016.00245

88. Barber PA, Demchuk AM, Zhang J, Buchan AM. Validity and reliability of a quantitative computed tomography score in predicting outcome of hyperacute stroke before thrombolytic therapy. ASPECTS Study Group. Alberta Stroke Programme Early CT Score. Lancet. 2000;355(9216):1670-4. https:// doi.org/10.1016/S0140-6736(00)02237-6

89. Beslow LA, Vossough A, Dahmoush HM, Kessler SK, Stainman R, Favilla CG, et al. Modified Pediatric ASPECTS Correlates with Infarct Volume in Childhood Arterial Ischemic Stroke. Front Neurol. 2012;3:122. https://doi.org/10.3389/fneur.2012.00122

90. Wusthoff CJ, Kessler SK, Vossough A, Ichord R, Zelonis S, Halperin A, et al. Risk of later seizure after perinatal arterial ischemic stroke: a prospective cohort study. Pediatrics. 2011;127(6):e1550-7. https://doi.org/10.1542/peds.2010-1577

91. Wouters A, Lemmens R, Dupont P, Thijs V. Wake-up stroke and stroke of unknown onset: a critical review. Front Neurol. 2014;5:153. https://doi.org/10.3389/fneur.2014.00153 
92. Aoki J, Kimura K, Iguchi Y, Shibazaki K, Sakai K, Iwanaga T. FLAIR can estimate the onset time in acute ischemic stroke patients. J Neurol Sci. 2010;293(1-2):39-44. https://doi.org/10.1016/j. jns.2010.03.011

93. Purushotham A, Campbell BC, Straka M, Mlynash M, Olivot JM, Bammer R, et al. Apparent diffusion coefficient threshold for delineation of ischemic core. Int J Stroke. 2015;10(3):348-53. https://doi. org/10.1111/ijs.12068

94. Zaharchuk G, El Mogy IS, Fischbein NJ, Albers GW. Comparison of arterial spin labeling and bolus perfusion-weighted imaging for detecting mismatch in acute stroke. Stroke. 2012;43(7):1843-8. https://doi.org/10.1161/STROKEAHA.111.639773

95. Bulder MM, Bokkers RP, Hendrikse J, Kappelle LJ, Braun KP, Klijn CJ. Arterial spin labeling perfusion MRI in children and young adults with previous ischemic stroke and unilateral intracranial arteriopathy. Cerebrovasc Dis. 2014;37(1):14-21. https://doi.org/10.1159/000355889

96. Yeon JY, Shin HJ, Seol HJ, Kim JS, Hong SC. Unilateral intracranial arteriopathy in pediatric stroke: course, outcome, and prediction of reversible arteriopathy. Stroke. 2014;45(4):1173-6. https://doi. org/10.1161/STROKEAHA.113.004125

97. Chen J, Licht DJ, Smith SE, Agner SC, Mason S, Wang S, et al. Arterial spin labeling perfusion MRI in pediatric arterial ischemic stroke: initial experiences. J Magn Reson Imaging. 2009;29(2):282-90. https://doi.org/10.1002/jmri.21641

98. Togao O, Mihara F, Yoshiura T, Tanaka A, Noguchi T, Kuwabara Y, et al. Cerebral hemodynamics in Moyamoya disease: correlation between perfusion-weighted MR imaging and cerebral angiography. AJNR Am J Neuroradiol. 2006;27(2):391-7.

99. So Y, Lee HY, Kim SK, Lee JS, Wang KC, Cho BK, et al. Prediction of the clinical outcome of pediatric moyamoya disease with postoperative basal/acetazolamide stress brain perfusion SPECT after revascularization surgery. Stroke. 2005;36(7):1485-9. https://doi.org/10.1161/01. STR.0000170709.95185.bl

100. Beslow LA, Licht DJ, Smith SE, Storm PB, Heuer GG, Zimmerman RA, et al. Predictors of outcome in childhood intracerebral hemorrhage: a prospective consecutive cohort study. Stroke. 2010;41(2): 313-8. https://doi.org/10.1161/STROKEAHA.109.568071

101. Meyer-Heim AD, Boltshauser E. Spontaneous intracranial haemorrhage in children: aetiology, presentation and outcome. Brain Dev. 2003;25(6):416-21. https://doi.org/10.1016/S0387-7604 (03)00029-9

102. Nabavizadeh SA, Edgar JC, Vossough A. Utility of susceptibility-weighted imaging and arterial spin perfusion imaging in pediatric brain arteriovenous shunting. Neuroradiology. 2014;56(10):877-84. https://doi.org/10.1007/s00234-014-1408-1

103. Lang SS, Beslow LA, Bailey RL, Vossough A, Ekstrom J, Heuer GG, et al. Follow-up imaging to detect recurrence of surgically treated pediatric arteriovenous malformations. J Neurosurg Pediatr. 2012;9(5):497-504. https://doi.org/10.3171/2012.1.PEDS11453

104. Wu YW, Hamrick SE, Miller SP, Haward MF, Lai MC, Callen PW, et al. Intraventricular hemorrhage in term neonates caused by sinovenous thrombosis. Ann Neurol. 2003;54(1):123-6. https://doi. org/10.1002/ana.10619

105. Knopman J, Tsiouris AJ, Souweidane MM. Atraumatic epidural hematoma secondary to a venous sinus thrombosis: a novel finding. J Neurosurg Pediatr. 2008;2(6):416-9. https://doi.org/10.3171/ PED.2008.2.12.416

106. Leach JL, Strub WM, Gaskill-Shipley MF. Cerebral venous thrombus signal intensity and susceptibility effects on gradient recalled-echo MR imaging. AJNR Am J Neuroradiol. 2007;28(5):940-5.

107. Dmytriw AA, Song JSA, Yu E, Poon CS. Cerebral venous thrombosis: state of the art diagnosis and management. Neuroradiology. 2018;60(7):669-85. https://doi.org/10.1007/s00234-018-2032-2

108. Wetzel SG, Kirsch E, Stock KW, Kolbe M, Kaim A, Radue EW. Cerebral veins: comparative study of CT venography with intraarterial digital subtraction angiography. AJNR Am J Neuroradiol. 1999;20(2):249-55.

109. Liang L, Korogi Y, Sugahara T, Onomichi M, Shigematsu Y, Yang D, et al. Evaluation of the intracranial dural sinuses with a 3D contrast-enhanced MP-RAGE sequence: prospective comparison with 2D-TOF MR venography and digital subtraction angiography. AJNR Am J Neuroradiol. 2001;22(3):481-92. 
110. Saindane AM, Mitchell BC, Kang J, Desai NK, Dehkharghani S. Performance of spin-echo and gradient-echo Tl-weighted sequences for evaluation of dural venous sinus thrombosis and stenosis. AJR Am J Roentgenol. 2013;201(1):162-9. https://doi.org/10.2214/AJR.12.9095

111. Forbes KP, Pipe JG, Heiserman JE. Evidence for cytotoxic edema in the pathogenesis of cerebral venous infarction. AJNR Am J Neuroradiol. 2001;22(3):450-5.

112. Chiras J, Dubs M, Bories J. Venous infarctions. Neuroradiology. 1985;27(6):593-600. https://doi. org/10.1007/BF00340857

113. Shellhaas RA, Smith SE, O'Tool E, Licht DJ, Ichord RN. Mimics of childhood stroke: characteristics of a prospective cohort. Pediatrics. 2006;118(2):704-9. https://doi.org/10.1542/peds.2005-2676

114. Ladner TR, Mahdi J, Gindville MC, Gordon A, Harris ZL, Crossman K, et al. Pediatric Acute Stroke Protocol Activation in a Children's Hospital Emergency Department. Stroke. 2015;46(8):2328-31. https://doi.org/10.1161/STROKEAHA.115.009961

115. Amlie-Lefond C, deVeber G, Chan AK, Benedict S, Bernard T, Carpenter J, et al. Use of alteplase in childhood arterial ischaemic stroke: a multicentre, observational, cohort study. Lancet Neurol. 2009;8(6):530-6. https://doi.org/10.1016/S1474-4422(09)70106-1

116. Roach ES, Golomb MR, Adams R, Biller J, Daniels S, Deveber G, et al. Management of stroke in infants and children: a scientific statement from a Special Writing Group of the American Heart Association Stroke Council and the Council on Cardiovascular Disease in the Young. Stroke. 2008;39(9): 2644-91. https://doi.org/10.1161/STROKEAHA.108.189696

117. Amlie-Lefond C, Shaw DWW, Cooper A, Wainwright MS, Kirton A, Felling RJ, et al. Risk of Intracranial Hemorrhage Following Intravenous tPA (Tissue-Type Plasminogen Activator) for Acute Stroke Is Low in Children. Stroke. 2020;51(2):542-8. https://doi.org/10.1161/STROKEAHA.119.027225

118. Rivkin MJ, deVeber G, Ichord RN, Kirton A, Chan AK, Hovinga CA, et al. Thrombolysis in pediatric stroke study. Stroke. 2015;46(3):880-5. https://doi.org/10.1161/STROKEAHA.114.008210

119. Sporns PB, Strater R, Minnerup J, Wiendl H, Hanning U, Chapot R, et al. Feasibility, Safety, and Outcome of Endovascular Recanalization in Childhood Stroke: The Save ChildS Study. JAMA Neurol. 2020;77(1):25-34. https://doi.org/10.1001/jamaneurol.2019.3403

120. Moharir MD, Shroff M, Stephens D, Pontigon AM, Chan A, MacGregor D, et al. Anticoagulants in pediatric cerebral sinovenous thrombosis: a safety and outcome study. Ann Neurol. 2010;67(5): 590-9. https://doi.org/10.1002/ana.21936

121. De Schryver EL, Kappelle LJ, Jennekens-Schinkel A, Boudewyn Peters AC. Prognosis of ischemic stroke in childhood: a long-term follow-up study. Dev Med Child Neurol. 2000;42(5):313-8. https:// doi.org/10.1017/S0012162200000554

122. deVeber G, Roach ES, Riela AR, Wiznitzer M. Stroke in children: recognition, treatment, and future directions. Semin Pediatr Neurol. 2000;7(4):309-17. https://doi.org/10.1053/spen.2000.20074

123. Ganesan V, Hogan A, Shack N, Gordon A, Isaacs E, Kirkham FJ. Outcome after ischaemic stroke in childhood. Dev Med Child Neurol. 2000;42(7):455-61.https://doi.org/10.1017/S0012162200000852

124. Boardman JP, Ganesan V, Rutherford MA, Saunders DE, Mercuri E, Cowan F. Magnetic resonance image correlates of hemiparesis after neonatal and childhood middle cerebral artery stroke. Pediatrics. 2005;115(2):321-6. https://doi.org/10.1542/peds.2004-0427

125. Kirton A, Deveber G, Pontigon AM, Macgregor D, Shroff M. Presumed perinatal ischemic stroke: vascular classification predicts outcomes. Ann Neurol. 2008;63(4):436-43. https://doi.org/10.1002/ ana.21334

126. Ganesan V, Ng V, Chong WK, Kirkham FJ, Connelly A. Lesion volume, lesion location, and outcome after middle cerebral artery territory stroke. Arch Dis Child. 1999;81(4):295-300. https:// doi.org/10.1136/adc.81.4.295 
